\title{
Social defeat predicts paranoid appraisals in people at high risk for psychosis
}

\author{
Lucia R. Valmaggia $^{\mathrm{a}, \mathrm{b}, *}$, Fern Day ${ }^{\mathrm{a}, \mathrm{b}}$, Philippa Garety ${ }^{\mathrm{a}, \mathrm{b}}$, Daniel Freeman ${ }^{\mathrm{c}}$, Angus Antley ${ }^{\mathrm{d}}$, Mel Slater ${ }^{\mathrm{d}, \mathrm{e}}$, \\ David Swapp $^{\mathrm{d}}$, Inez Myin-Germeys ${ }^{\mathrm{f}, 1}$, Philip McGuire ${ }^{\mathrm{a}, \mathrm{b}, 1}$ \\ a King's College London, Institute of Psychiatry, Psychology E' Neuroscience, United Kingdom \\ b South London and Maudsley NHS Foundation Trust, United Kingdom \\ c University of Oxford, Department of Psychiatry, United Kingdom \\ d Department of Computer Science, University College London, Gower Street, London, United Kingdom \\ e Event Lab, Faculty of Psychology, ICREA-University of Barcelona, Barcelona, Spain \\ ${ }^{\mathrm{f}}$ Maastricht University, The Netherlands
}

\section{A R T I C L E I N F O}

\section{Article history:}

Received 10 February 2015

Received in revised form 28 July 2015

Accepted 28 July 2015

Available online $\mathrm{xxxx}$

\section{Keywords:}

Ultra High Risk

Psychosis

Virtual Reality

Social defeat

Appraisal

Paranoia

\begin{abstract}
A B S T R A C T
Background: The experience of social defeat may increase the risk of developing psychotic symptoms and psychotic disorders. We studied the relationship between social defeat and paranoid appraisal in people at high risk for psychosis in an experimental social environment created using Virtual Reality (VR).

Method: We recruited UHR $(\mathrm{N}=64)$ participants and healthy volunteers $(\mathrm{N}=43)$. Regression analysis was used to investigate which baseline measures predicted paranoid appraisals during the VR experience.

Results: At baseline, UHR subjects reported significantly higher levels of social defeat than controls $(\mathrm{OR}=.957$, (CI) $.941-.973, \mathrm{p}<.000$ ). Following exposure to the VR social environment, the UHR group reported significantly more paranoid appraisals than the controls $(\mathrm{p}<.000)$. Within the UHR sample, paranoid appraisals were predicted by the level of social defeat at baseline, as well as by the severity of positive psychotic and disorganised symptoms. Conclusion: In people who are at high risk of psychosis, a history of social defeat is associated with an increased likelihood of making paranoid appraisals of social interactions. This is consistent with the notion that social defeat increases the risk of developing psychosis.
\end{abstract}

(c) 2015 Elsevier B.V. All rights reserved.

\section{Introduction}

Only a minority of individuals at Ultra High Risk (UHR) for psychosis goes on to develop a psychotic disorder. Recent research suggests that this may reflect increased exposure to or an increased vulnerability to social stressors (or both) in this subgroup (Corcoran et al., 2003, 2012; Thompson et al., 2007). However, the mechanisms by which stress influences the onset of psychosis remain unknown. Previous studies have suggested that lower perceived social rank is associated with paranoid ideation (Atherton et al., 2014; Freeman et al., 2014; Gilbert et al., 2005) and it has been proposed that the cumulative effect of prolonged exposure to social adversity and exclusion can lead to a state of 'social defeat', which may confer an increased risk of psychosis (Johnson et al., 2011; Selten et al., 2013; Selten and Cantor-Graae, 2005; Wicks et al., 2005). The concept of social defeat originates from animal research after it was observed that when an animal is put in a cage with another

\footnotetext{
* Corresponding author at: King's College London, Institute of Psychiatry, Psychology \& Neuroscience, Department of Psychology (PO 77), De Crespigny Park, SE5 8AF London, United Kingdom.

E-mail address: Lucia.Valmaggia@kcl.ac.uk (L.R. Valmaggia).

1 Joint last authors.
}

animal, they fight for dominance. If these fights occur over a prolonged period of time the defeated animal develops symptoms of stress and displays behaviour similar to that expressed in depressed humans (Bjorkqvist, 2001). In humans the definition of social defeat is more complex than in animals, because humans also generate a perception or appraisal of their position in the world (Gilbert, 2000; Gilbert and Gerlsma, 1999; Taylor et al., 2011). Appraisal theory proposes that the emotional response and physiological activation that occur in a situation are dependent on the appraisal, or meaning, given to what just occurred and on whether we think we will be able to cope with what just happened (Lazarus, 1991). In line with this theoretical framework, cognitive models of psychosis propose that early stressful events may result in a cognitive vulnerability which influences the interpretation and appraisal of daily stressors, and increases the likelihood that anomalous experiences develop into a psychotic disorder (Bentall et al., 2007; Freeman et al., 2002; Garety et al., 2001, 2007; Morrison and Wells, 2003).

It is difficult to assess real time appraisals in social situations in life. However, research using virtual reality to study in vivo and in situ reactions to social situations allows the measurement of real-time physiological activation and the assessment of thoughts, mood and symptoms as they occur (e.g., (Fornells-Ambrojo et al., 2013; Freeman et al., 2003, 2005; Stinson et al., 2010; Valmaggia et al., 2007; Veling et al., 2014)). 
The aim of the present study was to use Virtual Reality (VR) to contribute to examine the putative relationship between social defeat and paranoid appraisal in social situations in people at UHR for psychosis. Neither social defeat, nor its relationship with experimentally-induced paranoid ideation has been studied in UHR subjects before. Our first hypothesis was that UHR individuals would report higher levels of social defeat than controls. Our second prediction was that when exposed to a virtual social environment, the UHR group would report more paranoid appraisals than controls. Finally, we tested the hypothesis that within the UHR sample, the level of social defeat would predict the severity of paranoid ideation induced by the VR environment.

\section{Design and methods}

This was a cross-sectional comparison study. UHR participants and healthy controls (HCs) were compared to establish levels of social defeat and to study the relationship between social defeat and the appraisal of a VR social environment. Regression was then used to investigate which baseline measures predicted paranoid appraisals following the VR experience.

\subsection{Participants}

Participants meeting criteria for the UHR mental state for psychosis, aged 18-35, were recruited over a three year period from the Outreach and Support in South London (OASIS) service, a clinical service within the South London and Maudsley NHS Foundation Trust for people at heightened risk of developing psychosis (Fusar-Poli et al. 2013). UHR participants were identified according to PACE criteria (Yung et al., 1998) using the Comprehensive Assessment of At Risk Mental States CAARMS (Yung et al., 2005b).

HC participants were recruited from the same area of London through advertisements in the local press and the Mindsearch volunteers scheme at the Institute of Psychiatry, and were matched at group level for age, ethnicity, and gender. A cut-off score of 18 or higher on the PQ was applied to control for the possible presence of at risk mental states in HC.

\subsection{Measures}

\subsubsection{Socio-demographic information}

Socio-demographic and psychosocial variables were recorded during a clinical assessment using the First Contact With OASIS Questionnaire, a non-standardised questionnaire modelled on the Census 2001 collection form (Fusar-Poli et al., 2010). Social class was estimated using information on parental occupation according to the National Readership Survey social grades classification, and for the purposes of statistical comparison, participants' social class was assigned to one of two broad categories considered to represent 'middle/upper class' and 'working class' social classes.

\subsubsection{Comprehensive Assessment of the At Risk Mental State}

The Comprehensive Assessment of the At Risk Mental State (CAARMS) is a semi structured interview designed to assess attenuated psychotic symptoms in people at UHR. The scale has a total of 27 items which can be clustered in seven subscales and has been shown to have excellent reliability and validity (Yung et al., 2005b). Three subgroups of UHR can be identified using the CAARMS: genetic risk (schizotypy or a first-degree relative with a psychotic disorder, both with recently marked social decline), attenuated psychotic symptoms (subclinical psychotic symptoms, not fulfilling the criteria of psychosis), and patients who have experienced a brief limited intermittent psychosis (full-blown psychosis of $\leq 1$ week with spontaneous remission).

\subsubsection{Prodromal Questionnaire}

The Prodromal Questionnaire (PQ) (Loewy et al., 2005) is a selfreport screening questionnaire assessing prodromal and psychotic symptoms which aims to identify individuals who may benefit from a clinical diagnostic interview. The 92 true/false items can be divided into four major subscales: (1) positive symptoms; (2) negative symptoms; (3) disorganised symptoms; and (4) general symptoms. The PQ has good psychometric properties (Loewy et al., 2005).

\subsubsection{Entrapment and Defeat Scales}

The Social Entrapment and Defeat Scales are two 16 item scales measuring Entrapment and Defeat. Participants are asked to rate themselves a five point scale. An example of an Entrapment Item is: 'I am in a situation I feel trapped in'; $0=$ Not at all like me to $4=$ Extremely like me. An example item from the Defeat scale is: 'I feel that life has treated me like a punchbag'; $0=$ Never to $4=$ Always. Good psychometric properties for the Entrapment and Defeat Scales have been established (Gilbert and Allan, 1998). Previous research has suggested that the scales measure the same construct and should be used together (Taylor et al., 2009).

\subsubsection{Social Comparison Scale}

The Social Comparison Scale is an 11-item scale measuring how participants rate themselves from 1 to 10 in relation to others. For example, the scale asks 'In relation to others I generally feel: Incompetent 12345 678910 Competent'. The Social Comparison Scale has good psychometric properties (Allan and Gilbert, 1995).

\subsubsection{Social Defeat Composite Score}

The Entrapment and Defeat Scales and the Social Comparison Scale were added up to form a social defeat composite score. The internal consistency of the scale was high with a Cohen alpha of .878 .

\subsubsection{Depression Anxiety and Stress Scales}

The Depression, Anxiety and Stress Scale (DASS) is a 42-item measure of current (over the last week) states of depression, anxiety and stress (Lovibond and Lovibond, 1995). Each sub-scale consists of 14-items with a four point severity scale (ranging from $0=$ Did not apply to me to 3 = Applied to me very much or most of the time); higher scores indicate greater distress.

\subsubsection{Virtual Reality State Social Paranoia Scale}

The State Social Paranoia Scale (SSPS) (Freeman et al., 2007) is a 20 -item self report questionnaire examining paranoia, specifically paranoid ideation about virtual reality avatars. Each of the 20 items is rated on a five point scale from $1=$ 'Do not agree' to $5=$ 'Totally agree', with higher scores indicating higher endorsement. The SSPS asks about positive, neutral and paranoid appraisal of the VR environment. The SSPS examines recent paranoid thinking within a controlled social situation rather than assessing stable, trait paranoia. Based on the dataset, responses were grouped into four ordinal categories (corresponding to scores $<10 ; 11-15 ; 16-25$; $>26$ ).

\subsection{Transition to psychosis}

The onset of psychosis in the UHR group was defined using the criteria for transition to psychosis in the CAARMS (Yung et al., 2005a). A first episode diagnosis of psychosis was made by a member of the clinical team and confirmed by the team psychiatrist.

\subsection{The virtual reality environment}

The virtual environment (developed by the Department of Computer Science at University College London) was a tube train ride modelled on the interior of a London Underground train carriage (see Fig. 1), and was identical to that outlined in previous research (Freeman, 2008; Freeman et al., 2008). The environment was designed to be perceived as a neutral 


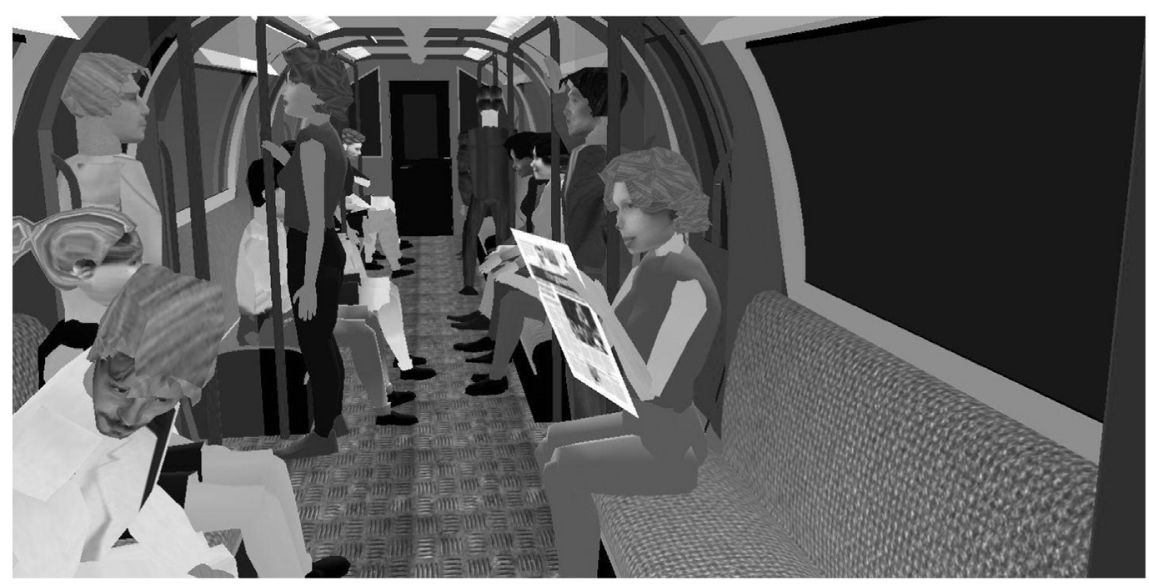

Fig. 1. Virtual Reality London Underground train carriage.

experience by a majority of the general population. The environment was displayed in colour via a lightweight headset; the display used was a Virtual Research VR 1280 (VR Systems, Aptos, California), with a resolution of $1280 \times 1024$ pixels, $60^{\circ}$ diagonal field of view and a refresh rate of $60 \mathrm{~Hz}$. Participants entered the train and were asked to remain on the train during the first stop, then disembark at the second stop. The journey time was approximately $4 \mathrm{~min}$. Background noises were played using a Creative sound card, mimicking noises associated with a London Underground train ride (e.g., a 'mind the closing doors' announcement when the doors were closing, fragments of passenger conversation, background noise of the moving train). Participants wore a headset and could move through the virtual environment by walking and whole body turning.

Prior to beginning the VR session, verbal instructions were provided by the researcher. Participants were asked to "Try and form an impression of what the people in the tube think about you and what you think about them". After the tube ride experience participants were asked to complete the post-VR measures.

\subsection{Statistical analyses}

Analyses were conducted using SPSS v.21 (SPSS Inc., Chicago, USA). Demographic differences between groups were calculated using chi square or independent samples t-test. Group differences in baseline variables were explored using the Mann-Whitney U test, Kruskal-Wallis $\mathrm{H}$, and independent samples t-test. Ordinal Logistic Regression (LOGIT) was applied to explore baseline of predictors of paranoid ideation in the VR environment.

\section{Results}

\subsection{Participant characteristics}

Sixty-five UHR participants and 45 HCs were recruited for the study. One $\mathrm{HC}$ participant was excluded from subsequent analysis due to a score in excess of 18 on the PQ positive symptom subscale. The VR equipment failed during the testing of one HC participant and one UHR participant, so their data were also excluded from the final analysis. The analysis thus involved data from 64 UHR and 43 HC participants.

The two groups were matched for age, gender, and ethnicity, as well as migration status. There were significant group differences in employment status, level of education and social class: unemployment was more common in UHR participants, whereas HC participants were more likely to have achieved a higher level of education and to have come from a 'middle class' background (see Table 1).

\subsection{Between group comparisons}

\subsubsection{Levels of social defeat in UHR subjects}

Consistent with our first hypothesis, the UHR group had higher levels of social defeat than the HC group (see Table 2).

\subsubsection{Depression, Anxiety, Stress an PQ at baseline}

As would be expected, there were also significant group differences in baseline levels of depression, anxiety and stress as well as all the subscales of the PQ between UHR and HC (See Table 2).

Table 1

Demographic characteristics of the sample.

\begin{tabular}{|c|c|c|c|}
\hline & $\begin{array}{l}\text { UHR } \\
\mathrm{N}=64\end{array}$ & $\begin{array}{l}\mathrm{HC} \\
\mathrm{N}=43\end{array}$ & Test \\
\hline \multirow[t]{2}{*}{ Age (years) } & Mean & & \\
\hline & $22.55(\mathrm{Sd} 4.01)$ & $24.02(\mathrm{Sd} 4.01)$ & $\begin{array}{l}t=-1.857(\text { df } 105) \\
p=.066\end{array}$ \\
\hline Gender & $\mathrm{N}(\%)$ & $\mathrm{N}(\%)$ & \\
\hline Male & $38(59.4)$ & $20(46.5)$ & $\begin{array}{l}\chi^{2}=.1 .714(\text { df } 1) \\
\mathrm{p}=.190\end{array}$ \\
\hline Female & $26(40.6)$ & $23(53.5)$ & \\
\hline \multicolumn{4}{|l|}{ Ethnicity } \\
\hline Black & 19 (29.7) & $10(23.3)$ & $\begin{array}{l}\chi^{2}=.899(\text { df } 3) \\
p=.826\end{array}$ \\
\hline White British & $23(35.9)$ & $16(37.2)$ & \\
\hline White other & $11(17.2)$ & $7(16.3)$ & \\
\hline Other & $11(17.2)$ & $10(23.3)$ & \\
\hline \multicolumn{4}{|l|}{ Employment status } \\
\hline Employed & $16(25)$ & $20(46.5)$ & $\begin{array}{l}\chi^{2}=27.297(\text { df } 2) \\
p<.001\end{array}$ \\
\hline Student & $12(18.8)$ & $20(46.5)$ & \\
\hline Unemployed & $36(56.3)$ & $3(7)$ & \\
\hline \multicolumn{4}{|l|}{ Level of education } \\
\hline $\begin{array}{l}\text { Higher education } \\
\text { or degree }\end{array}$ & $8(12.7)$ & $14(32.6)$ & $\begin{array}{l}\chi^{2}=12.314(\text { df } 3) \\
p=.006\end{array}$ \\
\hline $\begin{array}{l}\text { A-level or further } \\
\text { education }\end{array}$ & $33(52.9)$ & $25(58.1)$ & \\
\hline $\begin{array}{l}\text { GCSE level or } \\
\text { vocational }\end{array}$ & $18(28.6)$ & 4 (9.3) [Fisher] & \\
\hline No qualification & 4 (6.3) [Fisher] & 0 [Fisher] & \\
\hline \multicolumn{4}{|l|}{ NRS social grade } \\
\hline Higher & $19(33.3)$ & $25(61)$ & $\begin{array}{l}\chi^{2}=11.895(\operatorname{df} 2) \\
p=.003\end{array}$ \\
\hline Middle & $18(31.6)$ & $13(31.7)$ & \\
\hline Lower & $20(35.1)$ & 3 (7.3) [Fisher] & \\
\hline
\end{tabular}

UHR: Ultra High Risk; HCs: healthy controls; Sd: standard deviation. NRS: National Readership Survey social grade classification. 
Table 2

Between group comparisons.

\begin{tabular}{|c|c|c|c|c|c|}
\hline & & $\begin{array}{l}\text { UHR } \\
\mathrm{N}=64\end{array}$ & $\begin{array}{l}\mathrm{HC} \\
\mathrm{N}=43\end{array}$ & Test & Sig \\
\hline \multirow{4}{*}{ Composite score social defeat } & & 135.42 (Sd 39.09) & $78.30(\mathrm{Sd} 31.78)$ & $Z=-6.321$ & $\mathrm{p}<.001$ \\
\hline & Social defeat & $33.44(\mathrm{Sd} 14.16)$ & $15.05(\mathrm{Sd} 10.48)$ & $\mathrm{Z}=-6.083$ & $\mathrm{p}<.001$ \\
\hline & Social entrapment & $29.31(\mathrm{Sd} 17.31)$ & $9.83($ Sd 11.10) & $Z=-5.749$ & $\mathrm{p}<.001$ \\
\hline & Social comparison Scale (reversed scores) & 71.19 (Sd 16.74) & $53.42(\mathrm{Sd} 14.56)$ & $Z=-5.097$ & $\mathrm{p}<.001$ \\
\hline \multirow[t]{3}{*}{ DASS } & Depression & $21.10(\mathrm{Sd} 12.13)$ & $3.23(\mathrm{Sd} 4.08)$ & $\mathrm{Z}=-7.274$ & $\mathrm{p}<.001$ \\
\hline & Anxiety & $14.38(\mathrm{Sd} 10.32)$ & $2.05(\mathrm{Sd} 2.48)$ & $Z=-7.014$ & $\mathrm{p}<.001$ \\
\hline & Stress & $20.57(\mathrm{Sd} 12.06)$ & $5.72(\mathrm{Sd} 5.64)$ & $\mathrm{Z}=-6.325$ & $\mathrm{p}<.001$ \\
\hline \multirow[t]{4}{*}{ Prodromal Questionnaire } & Positive & 17.97 (Sd 11.45) & $4.51(\mathrm{Sd} 4.03)$ & $Z=-6.287$ & $\mathrm{p}<.001$ \\
\hline & Negative & $10.33(\mathrm{Sd} 5.10)$ & $2.37(\mathrm{Sd} 2.88)$ & $Z=-6.921$ & $\mathrm{p}<.001$ \\
\hline & Disorganised & $6.47(\mathrm{Sd} 3.92)$ & $2.42(\mathrm{Sd} 2.16)$ & $\mathrm{Z}=-5.236$ & $\mathrm{p}<.001$ \\
\hline & General & $7.14(3.96)$ & $1.93(\mathrm{Sd} 2.43)$ & $Z=-6.260$ & $\mathrm{p}<.001$ \\
\hline
\end{tabular}

UHR: Ultra High Risk; HCs: healthy controls; Sd: standard deviation.

\subsubsection{Paranoid appraisals in a VR social environment}

In line with our second prediction, following exposure to the virtual environment, the UHR group reported more paranoid appraisals than HC; HC participants were more likely to interpret the virtual environment as positive, while there were no significant differences in neutral interpretations (see Table 3).

\subsection{Relationship between social defeat and paranoid ideation}

Social Defeat was strongly associated with group status at baseline: the odds ratio was .957, with $95 \%$ confidence interval (CI) of .941-.973, $\mathrm{p}<.000$. We therefore decided to explore the relationship between paranoid ideation following VR only in the UHR group.

\subsubsection{Possible confounders}

To control for confounders a further analysis in the UHR group compared social defeat scores between potential confounders' variables. No significant differences were found in social defeat scores between different ethnic groups $\left(\chi^{2}(3)=1.259, \mathrm{p}=.739\right)$; employment status $\left(\chi^{2}(2)=4.447, \mathrm{p}=.108\right)$; level of education $\left(\chi^{2}(3)=4.567\right.$, $\mathrm{p}=.206)$; and NRS social grade $\left(\chi^{2}(2)=4.784, \mathrm{p}=.091\right)$.

\subsubsection{CAARMS subgroups}

The majority of UHR ( $N=48,75 \%)$ participants met criteria UHR presented with attenuated psychotic symptoms; eleven $17 \%$ met criteria for genetic risk with or without attenuated psychotic symptoms; and five (8\%) UHR individuals experienced a brief limited intermittent psychosis (BLIP). The mean social defeat score for the attenuated psychotic symptoms group was 136 (Sd 36.2); for the genetic risk group it was 149 (Sd 46.6) and for the BLIP group it was 89 (Sd 18.8). This difference between the three groups in social defeat scores was statistically significant $\left(\chi^{2}(2)=7.364, \mathrm{p}=.025\right)$.

\subsubsection{Predictors of social defeat}

Depression, Anxiety, Stress, PQ subscales, and Social Defeat were considered together in logistic regression with Paranoid Ideation as the dependent variable.

As hypothesised Social Defeat was a significant predictor of paranoid ideation with an odds ratio of 1.023 (95\% CI, 1.002 to 1.045 ), Wald

Table 3

Interpretation of VR environment, measured by the State Social Paranoia Scale.

\begin{tabular}{lllll}
\hline & ARMS & HC & Test & Sig \\
& $\mathrm{N}=64$ & $\mathrm{~N}=43$ & & \\
\hline Positive mean, SD & $10.44(4.52)$ & $13.52(4.15)$ & $\mathrm{Z}=-3.594$ & $\mathrm{p}<.001$ \\
Neutral mean, SD & $12.58(4.48)$ & $14.55(4.91)$ & $\mathrm{Z}=-1.942$ & $\mathrm{p}=.052$ \\
Paranoid mean, SD & $20.33(11.01)$ & $11.69(2.93)$ & $\mathrm{Z}=-4.382$ & $\mathrm{p}<.001$ \\
\hline
\end{tabular}

Sd: standard deviation. $\chi^{2}((1)=4.504, \mathrm{p}=.034)$. Paranoid ideation was also predicted by scores on the PQ Positive Subscale (OR of 1.240 (95\% CI, 1.105 to 1.390 ), Wald $\left.\chi^{2}(1)=13.476, \mathrm{p}<.000\right)$, and the PQ Disorganised Subscale (odds ratio of .588 (95\% CI, .443 to .781), Wald $\chi^{2}(1)=13.447$, $\mathrm{p}<000)$.

As illustrated in Table 4 baseline levels of Depression, Anxiety, and Stress and the PQ Negative and PQ General subscales were not significant predictors.

\subsection{Transition to psychosis}

Eight (12.5\%) participants made a transition to psychosis in the two years following taking part to the study. No significant difference in social defeat scores was found between those who did and those who did not develop a psychotic episode $(z=1.155, \mathrm{p}=.248)$.

Also no significant differences in paranoid ideation during the VR experiment were found between those who transitioned to a first episode of psychosis and those who did not $(\mathrm{z}=-1.361, \mathrm{p}=.173)$.

\section{Discussion}

Our first hypothesis was confirmed: the UHR sample had higher levels of social defeat than HC participants. Also as predicted, following exposure to the virtual social environment, the UHR group was more likely to make paranoid appraisals of their experiences than the HC group. Finally, within the UHR group, the level of social defeat, was a significant predictor of paranoid ideations in the VR environment. The levels of positive attenuated and disorganised symptoms at baseline were also predictors of paranoid appraisals, but depression and anxiety were not.

Although previous studies have reported high rates of adverse life events in UHR individuals (Addington et al., 2013; Bechdolf et al., 2010; Falukozi and Addington, 2012; Thompson et al., 2009; Tikka et al., 2013) and abnormalities in the hypothalamic-pituitary-adrenal (HPA) axis, the main bodily response to stress (Aiello et al., 2012; Day

Table 4

Ordinal regression between paranoid ideation and baseline variables.

\begin{tabular}{lrrrrl}
\hline & OR & CI $(95 \%)$ & & Wald $\chi^{2}(1)$ & Sign \\
\hline Social defeat & 1.023 & 1.002 & 1.045 & 4.505 & $\mathrm{p}=.034$ \\
DASS depression & 1.016 & .932 & 1.108 & .136 & $\mathrm{p}=.713$ \\
DASS anxiety & .976 & .861 & 1.107 & .141 & $\mathrm{p}=.707$ \\
DASS stress & 1.080 & .973 & 1.199 & 2.091 & $\mathrm{p}=.148$ \\
PQ positive & 1.240 & 1.105 & 1.390 & 13.476 & $\mathrm{p}<.001$ \\
PQ negative & 1.007 & .837 & 1.212 & .006 & $\mathrm{p}=.939$ \\
PQ disorganised & .588 & .443 & .781 & 13.447 & $\mathrm{p}<.000$ \\
PQ general & .963 & .753 & 1.232 & .088 & $\mathrm{p}=.767$ \\
\hline
\end{tabular}

OR: odd ratio, CI: confidence intervals; PQ: Prodromal Questionnaire; DASS: Depression, Anxiety and Stress Scale. 
et al., 2014; Walker et al., 2008), this study is the first to have shown that social defeat is more evident in UHR subjects than controls. The study also provided the first evidence that the level of social defeat predicted the extent to which UHR subjects made paranoid appraisals in a social setting. These findings are consistent with the proposal that social defeat is a key aetiological factor in the development of psychosis (Selten et al., 2013; Selten and Cantor-Graae, 2005). Social defeat is a particularly interesting risk factor, as research in experimental animals indicates that it is associated with neurobiological changes to brain dopamine function that are similar to those that occur in people at UHR for psychosis (Howes et al., 2009).

However, we also found that the severity of attenuated symptoms predicted VR-related paranoid ideation, and we cannot exclude the possibility that the association between social defeat and paranoid ideation was mediated by attenuated psychotic symptoms. The 2007 Adult Psychiatry Morbidly Survey, which surveyed 7353 participants from the English general population 16 years and older, showed an association between prolonged exposure to victimisation and other social adversities and paranoia (Bentall et al., 2012). Moreover, lower perceived social rank has been found to be associated with paranoid ideation in healthy controls (Freeman et al., 2005; Gilbert et al., 2005) and in people with early psychosis (Allison et al., 2013), and paranoia in real life has been found to be associated with VR related paranoid ideation in VR in people with psychosis (Veling et al., 2014).

It is possible that the presence of attenuated positive symptoms increased emotional reactivity to the VR environment, which predisposed UHR subjects to paranoid interpretations. Previous research has shown a link between stress reactivity and momentary increases in positive symptoms when exposed to daily stressor (Myin-Germeys et al., 2005), which was specifically related to positive psychotic symptoms (Lataster et al., 2013). Further work exploring the interplay between these factors (social defeat, baseline positive symptoms, and 'in the moment' paranoid ideation during the VR), would allow a better understanding of the elements that are critical to the processes underlying the experience of people at UHR in the VR environment. Unfortunately our sample size was not large enough to permit a mediation analysis to investigate the independence of positive symptoms and social defeat as predictors of paranoid ideation.

Attenuated disorganised symptoms showed a negative relationship with paranoid ideation in VR, in other words, lower levels of attenuated disorganised symptoms were associated with higher levels of paranoid ideation in the VR environment. Previous studies have reported that in people with schizophrenia, disorganised symptoms were associated with lower levels of mentalisation of other peoples' beliefs and intentions, while patients with paranoid symptoms were more likely to attribute malevolent intentions to others (Frith, 2004; Montag et al., 2011). Similar results were found in healthy participants with delusion proneness (Fyfe et al., 2008) and schizotypy (Barrantes-Vidal et al., 2013a,2013b). It is possible that our result tap into the same process, however further research is needed to confirm this.

Contrary to our expectations depression and anxiety at baseline were not significant predictors of paranoid ideation in the VR environment. This could be due to the multi-collinearity between depression, anxiety, stress and paranoid ideation. Previous studies examining the link between depression and anxiety in UHR people found that they were not predictive of transition to psychosis (Fusar-Poli et al., 2014; Woods et al., 2009). An experience sampling study assessing predictors of momentary increases in paranoia found momentary anxiety but not depression to be predictive of paranoia (Thewissen et al., 2011). However, as depression and anxiety correlate with social defeat their shared variance could have prevented these variables to reach significance in the regression. Indeed, recent evidence shows that avoidance and escape coping styles are associated with a higher level of negative symptoms, depression and anxiety both in UHR (Lee et al., 2011; Masillo et al., 2012) and in adolescent form the general population (Lin et al., 2011).
An intriguing finding was the difference in social defeat score among different subgroups of UHR, with the genetic risk group showing higher levels of social defeat, followed by the attenuated psychotic symptom group and the BLIP group reporting significantly lower scores. Caution is needed in interpreting this result as the BLIP group was small with only five participants. It has been suggested that BLIP may indicate that the individual is in the late prodromal phase and more likely to develop a psychotic episode (Nelson et al., 2011), however this does not explain why they would report lower scores of social defeat.

Social defeat at baseline and paranoid ideation in the VR environment did not distinguish those who went on to develop a psychotic episode, from those who did not. However it was not possible to investigate how social defeat and paranoid ideation relate to the risk of subsequently developing other mental health problems or long term functioning. However the sample size may not be large enough to provide sufficient power to identify differences between smaller subgroups defined by clinical and functional outcomes.

Our findings add to the recent literature (Johnson et al., 2011; Taylor et al., 2010, 2011) suggesting that the appraisal of defeat and entrapment contributes to the onset of psychopathology. Psychological models of psychosis suggest that adverse life events can influence the way we perceive ourselves, others, and the world around us. Alterations in appraisals have been found in people with schizophrenia (Garety et al., 2013; Peters et al., 2012) and in clinical and non-clinical individuals with psychotic experiences (Ward et al., 2014). It has been suggested that intervention approaches might focus on enhancing protective factors and resilience in coping with the consequences of social adversities (Gayer-Anderson and Morgan, 2013).

\section{Strengths and limitations}

A key strength of the study is that it explored the link between social defeat and paranoid ideation in an ecologically valid and standardised social environment that could be manipulated experimentally. Nevertheless, the study had some limitations. There were significant differences between UHR and HC participants in social class, employment status, and level of education, and it is possible that these factors contributed to the higher rate of social defeat in the UHR group. However a between group comparison in the UHR showed no significant differences with regard to these variables. Concerning the lack of prediction found for depression, anxiety and stress in predicting paranoid ideation in the VR environment, this should be interpreted with caution as the finding could be due to multi-collinearity. Finally, UHR individuals who present to early intervention teams may not be representative of all people at increased risk of developing psychosis, and the generalisability of results should be considered in light of this.

\section{Contributors}

Author LRV designed the study and wrote the protocol and secured funding for the study. Authors LRV \& FD managed the literature searches and statistical analysis. LRV wrote the first draft of the manuscript. DF, AA, MS, DS contributed to the study protocol and developed the virtual reality environment used in the study. PG, PMG, DF and IMG contributed to the manuscript. All authors have approved the final manuscript.

\section{Declaration of interest}

None.

\section{Ethical approval}

Research ethics approval was obtained from the National Research Ethics Service (Ethics REC number 08/H0722/45).

\section{Role of the funding source}

NARSAD Young Investigator Award from the Brain and Behaviour Research Foundation, and Peggy Pollack Research Fellowship from the Psychiatry Research Trust. Both awarded to Dr Valmaggia. 


\section{Conflict of interest}

The authors declare no conflict of interest.

\section{Acknowledgements}

Our special thanks go to the staff and service users of OASIS. Dr Valmaggia was supported by a NARSAD Young Investigator Award from the Brain and Behaviour Research Foundation, by a Peggy Pollack Research Fellowship from the Psychiatry Research Trust. Philip McGuire was supported by a grant from the Medical Research Council. The authors acknowledge financial support from the National Institute for Health Research (NIHR) Biomedical Research Centre for Mental Health at South London and Maudsley NHS Foundation Trust and King's College London. The views expressed are those of the author(s) and not necessarily those of the NHS, the NIHR or the Department of Health.

\section{References}

Addington, J., Stowkowy, J., Cadenhead, K.S., Cornblatt, B.A., McGlashan, T.H., Perkins, D.O., Seidman, L.J., Tsuang, M.T., Walker, E.F., Woods, S.W., Cannon, T.D., 2013. Early traumatic experiences in those at clinical high risk for psychosis. Early Interv. Psychiatry 7 (3), 300-305.

Aiello, G., Horowitz, M., Hepgul, N., Pariante, C.M., Mondelli, V., 2012. Stress abnormalities in individuals at risk for psychosis: a review of studies in subjects with familial risk or with "at risk" mental state. Psychoneuroendocrinology 37 (10), 1600-1613.

Allan, S., Gilbert, P., 1995. A social comparison scale: Psychometric properties and relationship to psychopathology. Personality and Individual Differences 19, 293-299.

Allison, G., Harrop, C., Ellett, L., 2013. Perception of peer group rank of individuals with early psychosis. Br. J. Clin. Psychol. 52 (1) 1-11.

Atherton, S., Antley, A., Evans, N., Cernis, E., Lister, R., Dunn, G., Slater, M., Freeman, D. 2014. Self-confidence and paranoia: an experimental study using an immersive virtual reality social situation. Behav. Cogn. Psychother. 1-9 [Epub ahead of print].

Barrantes-Vidal, N., Chun, C.A., Myin-Germeys, I., Kwapil, T.R., 2013a. Psychometric schizotypy predicts psychotic-like, paranoid, and negative symptoms in daily life. J. Abnorm. Psychol. 122 (4), 1077-1087.

Barrantes-Vidal, N., Gross, G.M., Sheinbaum, T., Mitjavila, M., Ballespi, S., Kwapil, T.R., 2013b. Positive and negative schizotypy are associated with prodromal and schizophreniaspectrum symptoms. Schizophr. Res. 145 (1-3), 50-55.

Bechdolf, A., Thompson, A., Nelson, B., Cotton, S., Simmons, M.B., Amminger, G.P., Leicester, S., Francey, S.M., McNab, C., Krstev, H., Sidis, A., McGorry, P.D., Yung, A.R. 2010. Experience of trauma and conversion to psychosis in an ultra-high-risk (prodromal) group. Acta Psychiatr. Scand. 121 (5), 377-384.

Bentall, R.P., Fernyhough, C., Morrison, A.P., Lewis, S., Corcoran, R., 2007. Prospects for a cognitive-developmental account of psychotic experiences. Br. J. Clin. Psychol. 46 (Pt 2), 155-173.

Bentall, R.P., Wickham, S., Shevlin, M., Varese, F., 2012. Do specific early-life adversities lead to specific symptoms of psychosis? A study from the 2007 the Adult Psychiatric Morbidity Survey. Schizophr. Bull. 38 (4), 734-740.

Bjorkqvist, K., 2001. Social defeat as a stressor in humans. Physiol. Behav. 73 (3), 435-442.

Corcoran, C., Walker, E., Huot, R., Mittal, V., Tessner, K., Kestler, L., Malaspina, D., 2003. The stress cascade and schizophrenia: etiology and onset. Schizophr. Bull. 29 (4), 671-692.

Corcoran, C.M., Smith, C., McLaughlin, D., Auther, A., Malaspina, D., Cornblatt, B., 2012. HPA axis function and symptoms in adolescents at clinical high risk for schizophrenia. Schizophr. Res. 135 (1-3), 170-174.

Day, F.L., Valmaggia, L.R., Mondelli, V., Papadopoulos, A., Papadopoulos, I., Pariante, C.M., McGuire, P., 2014. Blunted cortisol awakening response in people at ultra high risk of developing psychosis. Schizophr. Res. 158 (1-3), 25-31.

Falukozi, E., Addington, J., 2012. Impact of trauma on attenuated psychotic symptoms. Psychosis 4 (3), 203-212.

Fornells-Ambrojo, M., Freeman, D., Slater, M., Swapp, D., Antley, A., Barker, C., 2013. How do people with persecutory delusions evaluate threat in a controlled social environment? A qualitative study using virtual reality. Behav. Cogn. Psychother. 1-19.

Freeman, D., 2008. Studying and treating schizophrenia using virtual reality: a new paradigm. Schizophr. Bull. 34 (4), 605-610.

Freeman, D., Garety, P.A., Kuipers, E., Fowler, D., Bebbington, P.E., 2002. A cognitive model of persecutory delusions. Br. J. Clin. Psychol. 41 (Pt 4), 331-347.

Freeman, D., Slater, M., Bebbington, P.E., Garety, P.A., Kuipers, E., Fowler, D., Met, A., Read, C.M., Jordan, J., Vinayagamoorthy, V., 2003. Can virtual reality be used to investigate persecutory ideation? J. Nerv. Ment. Dis. 191 (8), 509-514.

Freeman, D., Garety, P.A., Bebbington, P., Slater, M., Kuipers, E., Fowler, D., Green, C., Jordan, J., Ray, K., Dunn, G., 2005. The psychology of persecutory ideation II: a virtual reality experimental study. J. Nerv. Ment. Dis. 193 (5), 309-315.

Freeman, D., Pugh, K., Green, C., Valmaggia, L., Dunn, G., Garety, P., 2007. A measure of state persecutory ideation for experimental studies. J. Nerv. Ment. Dis. 195 (9), 781-784.

Freeman, D., Pugh, K., Antley, A., Slater, M., Bebbington, P., Gittins, M., Dunn, G., Kuipers, E., Fowler, D., Garety, P., 2008. Virtual reality study of paranoid thinking in the general population. Br. J. Psychiatry 192 (4), 258-263.

Freeman, D., Evans, N., Lister, R., Antley, A., Dunn, G., Slater, M., 2014. Height, social comparison, and paranoia: an immersive virtual reality experimental study. Psychiatry Res. 218 (3), 348-352.

Frith, C.D., 2004. Schizophrenia and theory of mind. Psychol. Med. 34 (3), 385-389.

Fusar-Poli, P., Byrne, M., Valmaggia, L., Day, F., Tabraham, P., Johns, L., McGuire, P., Team, O., 2010. Social dysfunction predicts two years clinical outcome in people at ultra high risk for psychosis. J. Psychiatr. Res. 44 (5), 294-301.

Fusar-Poli, P., Byrne, M., Badger, S., Valmaggia, L.R., McGuire, P.K., 2013. Outreach and support in South London (OASIS), 2001-2011: ten years of early diagnosis and treatment for young individuals at high clinical risk for psychosis. Eur. Psychiatry 28 (5), 315-326.

Fusar-Poli, P., Nelson, B., Valmaggia, L., Yung, A.R., McGuire, P.K., 2014. Comorbid depressive and anxiety disorders in 509 individuals with an at-risk mental state: impact on psychopathology and transition to psychosis. Schizophr. Bull. 40 (1), 120-131.

Fyfe, S., Williams, C., Mason, O.J., Pickup, G.J., 2008. Apophenia, theory of mind and schizotypy: perceiving meaning and intentionality in randomness. Cortex 44 (10), 1316-1325.

Garety, P.A., Kuipers, E., Fowler, D., Freeman, D., Bebbington, P.E., 2001. A cognitive model of the positive symptoms of psychosis. Psychol. Med. 31 (2), 189-195.

Garety, P.A., Bebbington, P., Fowler, D., Freeman, D., Kuipers, E., 2007. Implications for neurobiological research of cognitive models of psychosis: a theoretical paper. Psychol. Med. 37 (10), 1377-1391.

Garety, P.A., Gittins, M., Jolley, S., Bebbington, P., Dunn, G., Kuipers, E., Fowler, D., Freeman D., 2013. Differences in cognitive and emotional processes between persecutory and grandiose delusions. Schizophr. Bull. 39 (3), 629-639.

Gayer-Anderson, C., Morgan, C., 2013. Social networks, support and early psychosis: a systematic review. Epidemiol. psychiatr. Sci. 22 (2), 131-146.

Gilbert, P., 2000. Varieties of submissive behavior as forms of social defense: their evolution and role in depression. In: Sloman, L., Gilbert, P. (Eds.), Subordination and Defeat: An Evolutionary Approach to Mood Disorders and Their Therapy Erlbaum, pp. 3-45 (Mahwah, NJ).

Gilbert, P., Allan, S., 1998. The role of defeat and entrapment (arrested flight) in depression: an exploration of an evolutionary view. Psychol. Med. 28 (3), 585-598.

Gilbert, P., Gerlsma, C., 1999. Recall of shame and favouritism in relation to psychopathology. Br. J. Clin. Psychol. 38 (Pt 4), 357-373.

Gilbert, P., Boxall, M., Cheung, M., Irons, C., 2005. The relation of paranoid ideation and social anxiety in a mixed clinical population. Clin. Psychol. Psychother. 12, 124-133.

Howes, O.D., Montgomery, A.J., Asselin, M.C., Murray, R.M., Valli, I., Tabraham, P., BramonBosch, E., Valmaggia, L., Johns, L., Broome, M., McGuire, P.K., Grasby, P.M., 2009. Elevated striatal dopamine function linked to prodromal signs of schizophrenia. Arch. Gen. Psychiatry 66 (1), 13-20.

Johnson, J., Gooding, P.A., Wood, A.M., Taylor, P.J., Tarrier, N., 2011. Trait reappraisal amplifies subjective defeat, sadness, and negative affect in response to failure versus success in nonclinical and psychosis populations. J. Abnorm. Psychol. 120 (4), 922-934.

Lataster, T., Valmaggia, L., Lardinois, M., van Os, J., Myin-Germeys, I., 2013. Increased stress reactivity: a mechanism specifically associated with the positive symptoms of psychotic disorder. Psychol. Med. 43 (7), 1389-1400.

Lazarus, R.S., 1991. Progress on a cognitive-motivational-relational theory of emotion. Am. Psychol. 46 (8), 819-834.

Lee, S., Kim, K., Park, J., Park, J., Kim, B., Kang, J., Lee, E., An, S., Kwon, J., 2011. Coping strategies and their relationship to psychopathologies in people at ultra high risk for psychosis and with schizophrenia. J. Nerv. Ment. Dis. 199, 106-110.

Lin, A., Wigman, J., Nelson, B. Vollebergh, W., van Os, J., Baksheev, G., Ryan, J., Raaijmakers, Q., Thompson, A., Yung, A., 2011. The relationship between coping and subclinical psychotic experiences in adolescents from the general population: a longitudinal study. Psychol. Med. 41 (12), 2535-2546.

Loewy, R.L., Bearden, C.E., Johnson, J.K., Raine, A., Cannon, T.D., 2005. The prodromal questionnaire (PQ): preliminary validation of a self-report screening measure for prodromal and psychotic syndromes. Schizophr. Res. 79 (1), 117-125.

Lovibond, P.F., Lovibond, S.H., 1995. The structure of negative emotional states: comparison of the Depression Anxiety Stress Scales (DASS) with the Beck Depression and Anxiety Inventories. Behav. Res. Ther. 33 (3), 335-343.

Masillo, A., Day, F., Laing, J., Howes, O., Fusar-Poli, P., Byrne, M., Bhattacharyya, S., Fiori Nastro, P., Girardi, P., McGuire, P.K., Valmaggia, L.R., 2012. Interpersonal sensitivity in the at-risk mental state for psychosis. Psychol. Med. 42 (9), 1835-1845.

Montag, C., Dziobek, I., Richter, I.S., Neuhaus, K., Lehmann, A., Sylla, R., Heekeren, H.R., Heinz, A., Gallinat, J., 2011. Different aspects of theory of mind in paranoid schizophrenia: evidence from a video-based assessment. Psychiatry Res. 186 (2-3), 203-209.

Morrison, A.P., Wells, A., 2003. A comparison of metacognitions in patients with hallucinations, delusions, panic disorder, and non-patient controls. Behav. Res. Ther. 41 (2), 251-256.

Myin-Germeys, I., Delespaul, P., van Os, J., 2005. Behavioural sensitization to daily life stress in psychosis. Psychol. Med. 35 (5), 733-741.

Nelson, B., Yuen, K., Yung, A.R., 2011. Ultra high risk (UHR) for psychosis criteria: are there different levels of risk for transition to psychosis? Schizophr. Res. 125 (1), 62-68.

Peters, E., Lataster, T., Greenwood, K., Kuipers, E., Scott, J., Williams, S., Garety, P., MyinGermeys, I., 2012. Appraisals, psychotic symptoms and affect in daily life. Psychol. Med. 42 (5), 1013-1023.

Selten, J.P., Cantor-Graae, E., 2005. Social defeat: risk factor for schizophrenia? Br J. Psychiatry J. Ment. Sci. 187, 101-102.

Selten, J.P., van der Ven, E., Rutten, B.P., Cantor-Graae, E., 2013. The social defeat hypothesis of schizophrenia: an update. Schizophr. Bull. 39 (6), 1180-1186.

Stinson, K., Valmaggia, L.R., Antley, A., Slater, M., Freeman, D., 2010. Cognitive triggers of auditory hallucinations: an experimental investigation. J. Behav. Ther. Exp. Psychiatry 41 (3), 179-184

Taylor, P.J., Wood, A.M., Gooding, P., Johnson, J., Tarrier, N., 2009. Are defeat and entrapment best defined as a single construct? Personal. Individ. Differ. 47, 795-797.

Taylor, P.J., Gooding, P.A., Wood, A.M., Johnson, J., Pratt, D., Tarrier, N., 2010. Defeat and entrapment in schizophrenia: the relationship with suicidal ideation and positive psychotic symptoms. Psychiatry Res. 178 (2), 244-248.

Taylor, P.J., Gooding, P., Wood, A.M., Tarrier, N., 2011. The role of defeat and entrapment in depression, anxiety, and suicide. Psychol. Bull. 137 (3), 391-420.

Thewissen, V., Bentall, R.P., Oorschot, M., J., A.C., van Lierop, T., van Os, J., Myin-Germeys, I., 2011. Emotions, self-esteem, and paranoid episodes: an experience sampling study Br. J. Clin. Psychol. 50 (2), 178-195. 
Thompson, K.N., Phillips, L.J., Komesaroff, P., Yuen, H.P., Wood, S.J., Pantelis, C., Velakoulis, D., Yung, A.R., McGorry, P.D., 2007. Stress and HPA-axis functioning in young people at ultra high risk for psychosis. J. Psychiatr. Res. 41 (7), 561-569.

Thompson, J.L., Kelly, M., Kimhy, D., Harkavy-Friedman, J.M., Khan, S., Messinger, J.W. Schobel, S., Goetz, R., Malaspina, D., Corcoran, C., 2009. Childhood trauma and prodromal symptoms among individuals at clinical high risk for psychosis. Schizophr. Res. 108 (1-3), 176-181.

Tikka, M, Luutonen, S, Ilonen, T. Tuominen, L, Kotimaki, M., Hankala, J Salokangas, R.K 2013. Childhood trauma and premorbid adjustment among individuals at clinical high risk for psychosis and normal control subjects. Early Interv. Psychiatry 7 (1), 51-57.

Valmaggia, L.R., Freeman, D., Green, C., Garety, P., Swapp, D., Antley, A., Prescott, C., Fowler, D., Kuipers, E., Bebbington, P., Slater, M., Broome, M., McGuire, P.K., 2007. Virtual reality and paranoid ideations in people with an 'at-risk mental state' for psychosis. Br. J. Psychiatry 191, S63-S68.

Veling, W., Brinkman, W.P., Dorrestijn, E., van der Gaag, M., 2014. Virtual reality experiments linking social environment and psychosis: a pilot study. Cyberpsychol. Behav. Soc. Netw. 17 (3), 191-195.

Walker, E., Mittal, V., Tessner, K., 2008. Stress and the hypothalamic pituitary adrenal axis in the developmental course of schizophrenia. Annu. Rev. Clin. Psychol. 4, 189-216.
Ward, T.A., Gaynor, K.J., Hunter, M.D., Woodruff, P.W., Garety, P.A., Peters, E.R., 2014. Appraisals and responses to experimental symptom analogues in clinical and nonclinical individuals with psychotic experiences. Schizophr. Bull. 40 (4), 845-855.

Wicks, S., Hjern, A., Gunnell, D., Lewis, G., Dalman, C., 2005. Social adversity in childhood and the risk of developing psychosis: a national cohort study. Am. J. Psychiatry 162 (9), 1652-1657.

Woods, S.W., Addington, J., Cadenhead, K.S., Cannon, T.D., Cornblatt, B.A., Heinssen, R., Perkins, D.O., Seidman, L.J., Tsuang, M.T., Walker, E.F., McGlashan, T.H., 2009. Validity of the prodromal risk syndrome for first psychosis: findings from the North American Prodrome Longitudinal Study. Schizophr. Bull. 35 (5), 894-908.

Yung, A.R., Phillips, L.J., McGorry, P.D., McFarlane, C.A., Francey, S., Harrigan, S., Patton, G.C., Jackson, H.J., 1998. Prediction of psychosis. A step towards indicated prevention of schizophrenia. Br. J. Psychiatry Suppl. 172 (33), 14-20.

Yung, A.R., Yuen, H.P., McGorry, P.D., Phillips, L.J., Kelly, D., Dell'Olio, M., Francey, S.M., Cosgrave, E.M., Killackey, E., Stanford, C., Godfrey, K., Buckby, J., 2005a. Mapping the onset of psychosis: the Comprehensive Assessment of At-Risk Mental States. Aust. N. Z. J. Psychiatry 39 (11-12), 964-971.

Yung, A.R., Yuen, H.P., McGorry, P.D., Phillips, L.J., Kelly, D., Dell'Olio, M., Francey, S.M., Cosgrave, E.M., Killackey, E., Stanford, C., Godfrey, K., Buckby, J., 2005b. Mapping the onset of psychosis: the Comprehensive Assessment of At-Risk Mental States. Aust. N. Z. J. Psychiatry 39 (11-12), 964-971. 